10. Gillis D. The people assessing their health (PATH) project: tools for community health impact assessment. Can J Public Health 1999; 90(Suppl): S53-S56.

11. Mittelmark M, Gillis D, Hsu-Hage B. Community development: the role of HIA. In: Kemm J, Parry J, Palmer S, eds. Health impact assessment. Oxford: Oxford University Press, 2004: 143-52.

12. Liverpool Public Health Observatory HIA reports. At: www. liv.ac.uk/PublicHealth/obs, accessed 16 August 2005.

13. National Assembly for Wales. Developing health impact assessment for Wales. Cardiff: Health Promotion Division, National Assembly for Wales, 1999.

14. Labonté R. Health promotion and empowerment: practice frameworks. Toronto: Toronto Centre for Health Promotion, University of Toronto and ParticipAction, 1993.
15. Scott-Samuel A, Birley M, Ardern K. The Merseyside guidelines for health impact assessment. $2^{\text {nd }}$ edition. Liverpool: IMPACT, University of Liverpool, 2001. Available from www.ihia.org.uk/document/merseyguide3.pdf.

16. Parry J, Wright J. Community participation in health impact assessments: Intuitively appealing but practically difficult. Bull World Health Organ 2003; 81: 388.

17. O'Keefe E, Scott-Samuel A. Health impact assessment and globalization. In: Kawachi I, Wamala S, eds. Globalization and health. New York: Oxford University Press (in press).

18. O'Keefe E, Scott-Samuel A. Human rights and wrongs: Could health impact assessment help? J Law Med Ethics 2002; 30: 734-8.

19. Dannenberg A et al. Growing the field of health impact assessment in the United States: An agenda for research and practice. Am J Public Health (in press).

\title{
HEALTH IMPACT ASSESSMENT IN AUSTRALIA
}

\section{Mary Mahoney \\ HIA Research Unit \\ Deakin University}

A recently published paper which describes the status of health impact assessment (HIA) in Australia in 2003 provides a vantage point from which to see how rapidly HIA is developing across the country. ${ }^{1}$ When the report Health impact assessment: a tool for policy development in Australia was released in 2002 there was little use of HIA beyond environmental management applications. ${ }^{2}$ By late 2005, most states and territories are undertaking a variety of HIA activities either routinely or experimentally. Traditional divisions between environmental project-level applications that focus on health protection and public health policy-level applications that focus on health promotion, are largely disappearing. These are being replaced by a growing understanding of the need for complementarity in approach and cross-sectoral working. This is not to say that there are high levels of activity, but both awareness and action are increasing.

In terms of the development of HIA in Australia, the period between 1999 and 2003 was characterised by a desire to strengthen the health component in environmental assessment processes and procedures, broaden the interpretation of health through the introduction of the enHEALTH Health Impact Assessment Guidelines $(2001)^{3}$ and commence discussions about the strategic positioning of HIA as a tool for use by governments. In 2004 two national events helped to strengthen intersectoral understanding of HIA: a three-day national HIA workshop in Brisbane co-hosted by the Queensland Public Health Forum, the National Public Health Partnership (NPHP), Queensland Health and enHEALTH and a two-day equity-focused HIA workshop in Sydney hosted by the Australasian Collaboration for Health Equity Impact Assessment
(ACHEIA) and funded by the federal government and NSW Health. Both events allowed for jurisdictional and crossdisciplinary conversations about work being undertaken and the exploration of enablers and barriers. They also provided the chance for a deeper understanding of HIA and its future role to be developed.

The list of developments in the field of HIA that are described in this article has been collated from three sources: submissions prepared by each jurisdiction for the Brisbane conference; state submissions on HIA for inclusion in a national HIA poster presented at the $6^{\text {th }} \mathrm{UK}$ and Ireland HIA Conference in late 2004 ${ }^{4}$; and presentations of completed HIAs and case studies delivered at both these conferences.

\section{EMERGING TRENDS IN HIA ACROSS AUSTRALIA}

- Intersectoral action and partnership working - this is occurring at two levels: organisational and professional. At the organisational level, consortia of organisations such as local and state governments, developers, researchers and community representatives are working together to explore the health impacts of large urban developments, including developmental work in NSW and Queensland. At the professional level, individuals and teams of people (for example, land use planners, statutory planners, strategic planners, public health planners and community health planners) are beginning to work together as the links between their respective roles is increasingly being articulated, both within and between organisations.

- A focus on community regeneration-exploration of the role of HIA in the planning stages of state government regeneration schemes in disadvantaged communities, particularly developmental work in NSW 
(see Harris-Roxas and Simpson in this issue), as well as increased understanding of the role that HIA can play in community decision making about factors affecting the community's health, particularly in Victoria and Western Australia.

- Development of new frameworks for applying HIA and strengthening the focus on the determinants of health through the development of an equity-focused HIA framework (by ACHEIA) ${ }^{5}$; the strengthening of HIA guidelines (through enHEALTH ${ }^{3}$ ); refinement of the legislative and administrative guidelines, both of which are still being refined (through NPHP); and coordination of state level activity (in states such as Queensland) and increased attention to incorporating Aboriginal health needs and interests in health policies, programs, services and strategies through the routine use of, for instance, the NSW Health Aboriginal Health Impact Statement. ${ }^{6}$

- Investment in HIA research and developmental projects. This includes funding by Queensland Health for projects that improve the uptake of HIA methodologies in government (for example, the development of a toolkit ${ }^{7}$ ), funding in New South Wales to undertake developmental projects and build capacity, and a research grant in Victoria to consider the role of HIA in local government planning processes. Ongoing investment in the professional development of staff with portfolio responsibilities for HIA, health inequalities and interdepartmental links, continues in most states.

- Increased attention to integrated approaches through exploration of the potential links between different forms of impact assessment (for example, social impact assessment, human impact assessment, integrated impact assessment and strategic environment assessment); through strengthening health components in environmental impact assessment practices, particularly in Tasmania, South Australia and Western Australia; and through the application of HIA in nonhealth-sector policy contexts in South Australia and the Northern Territory.

- Exploration of the options for the application of HIA in local government in Victoria and Queensland.

- Increased focus on building capacity and sharing experiences, particularly through: the Brisbane conference; the equity-focussed HIA workshop; jurisdictional meetings; the HIA enews and other resources available through the specialist websites (see list at the end of this paper); and increased enrolment and demand for training programs. All states have been represented at each of the main HIA events in the last 12 months and jurisdictional meetings have focussed on shared information and the developments occurring within each state and territory.

As well as ongoing developments within each of these themes, there are two issues that will need to be urgently addressed by most jurisdictions as interest in HIA grows. The development of appropriate training, workforce development programs and broader capacity within organisations to undertake HIA is a growing concern. Similarly, the development of formal and informal routes into key areas of decision making within government that have the potential to impact on health, and which are outside of traditional inter-sectoral links, will continue to be a challenge for many departments of health. We continue, with the generous support of international organisations and individuals, to learn from the experiences of others who have faced these challenges and succeeded.

For more information on:

- specific HIA activities in each state of Australia, see enews and the HIA poster at http://chetre.med.unsw.edu.au/hia

- the equity-focused workshop, including access to the framework document and the literature review, refer to Aldrich et al, 'Building an equity focus in health impact assessment' in this issue of the NSW Public Health Bulletin

- the national HIA workshop in Brisbane, contact Queensland Health.

See also the HIA website at Deakin University at www.deakin.edu.au/hia, accessed 4 November 2005.

\section{REFERENCES}

1. Wright J, Parry J et al. (2005). Institutionalizing policy-level health impact assessment in Europe: Is coupling health impact assessment with strategic environmental assessment the next step forward? Bulletin of the World Health Organization 2005; 83(6): 472-7.

2. Mahoney M, Durham G et al. Health impact assessment: a tool for policy development in Australia. Melbourne: Deakin University, 2002.

3. enHealth. Health impact assessment guidelines. Canberra: National Public Health Partnership, Commonwealth Department of Health and Aged Care, 2001. Available from www.health.gov.au/internet/wcms/Publishing.nsf/Content/ health-pubhlth-publicat-document-metadata-env_impact. htm/\$FILE/env_impact.pdf.

4. Simpson S, Mahoney M, Dixon L, Kelly M, Lynch V, Katscherian D et al. Health impact assessment in Australia: Context and diversity. Sydney, Centre for Health Equity Training Research and Evaluation; poster presented at the $6^{\text {th }}$ UK and Ireland Health Impact Assessment Conference, Birmingham, UK, October 2004.

5. Mahoney M, Simpson S, Harris E, Aldrich R, StewartWilliams J. Equity focused health impact assessment framework. Australasian Collaboration for Health Equity Impact Assessment, 2004. Available at http://chetre.med. unsw.edu.au/files/EFHIA_Framework.pdf.

6. NSW Department of Health. NSW Health Aboriginal Health Impact Statement and Guidelines. Sydney, NSW Health, 2003, available at www.health.nsw.gov.au/pubs/a/pdf/ab_impact_ state_book.pdf, accessed 4 November 2005.

7. Queensland Health. Health impact assessment: A guide for service providers. Queensland Health, Brisbane, 2003, available at www.health.qld.gov.au/phs/Documents/ sphun/20364.pdf, accessed 4 October 2005. 좀 